\section{Check for updates}

Cite this: J. Mater. Chem. A, 2019, 7, 2908

\title{
Electrochromic $\mathrm{WO}_{3}$ thin films attain unprecedented durability by potentiostatic pretreatment $\dagger$
}

\author{
Miguel A. Arvizu, (D) $\ddagger^{a}$ Hui-Ying Qu, (D) $\ddagger^{a b}$ Umut Cindemir, (D) ${ }^{a}$ Zhen Qiu, (D) a \\ Edgar A. Rojas-González, (DD ${ }^{a}$ Daniel Primetzhofer, (iD ${ }^{c}$ Claes G. Granqvist, ${ }^{a}$ \\ Lars Österlund (iD) a and Gunnar A. Niklasson (D)*a
}

\begin{abstract}
Electrochromic windows and glass facades are able to impart energy efficiency jointly with indoor comfort and convenience. Long-term durability is essential for practical implementation of this technology and has recently attracted broad interest. Here we show that a simple potentiostatic pretreatment of sputterdeposited thin films of amorphous $\mathrm{WO}_{3}$-the most widely studied electrochromic material-can yield unprecedented durability for charge exchange and optical modulation under harsh electrochemical cycling in a Li-ion-conducting electrolyte and effectively evades harmful trapping of Li. The pretreatment consisted of applying a voltage of $6.0 \mathrm{~V}$ vs. $\mathrm{Li} / \mathrm{Li}^{+}$for several hours to a film backed by a transparent conducting $\ln _{2} \mathrm{O}_{3}: \mathrm{Sn}$ layer. Associated compositional and structural modifications were probed by several techniques, and improved durability was associated with elemental intermixing at the $\mathrm{WO}_{3} / \mathrm{ITO}$ and ITO/glass boundaries as well as with carbonaceous solid-electrolyte interfacial layers on the $\mathrm{WO}_{3}$ films. Our work provides important new insights into long-term durability of ion-exchange-based devices.
\end{abstract}

Received 5th October 2018

Accepted 9th January 2019

DOI: 10.1039/c8ta09621j

rsc.li/materials-a
Electrochromics ${ }^{\mathbf{1 0 - 1 2}}$ is the technology of choice for smart windows ${ }^{\mathbf{1 3 - 1 5}}$ and offers possibilities to electrically regulate the optical transmittance, reversibly and persistently, between widely separated limits. By far the most widely used and studied electrochromic device for this purpose embodies a five-layer construction with a W-oxide-based thin film separated from a Ni-oxide-based thin film by a transparent inorganic or polymeric ion conductor; this three-layer stack is positioned between transparent electrically conducting thin layers. ${ }^{13}$ Optical modulation is accomplished when voltage is applied between the transparent conductors; darkening takes place when charge is shuttled from $\mathrm{Ni}$ oxide to $\mathrm{W}$ oxide while bleaching occurs when charge is moved in the opposite direction. ${ }^{16}$ Obviously, an electrochromic smart window must be cheap, robust and permit practical operation for decades without essential performance loss. It is therefore not surprising that recent work has focused on increased durability of W-oxide-based and Ni-oxide-based thin films, which has been accomplished for example by adding titanium to $\mathrm{W}$ oxide $\mathrm{e}^{17-22}$ and nitrogen, ${ }^{23}$ cobalt $^{24}$ or iridium ${ }^{25}$ to $\mathrm{Ni}$ oxide. Other efforts to increase durability have included the use of blocking layers, ${ }^{26}$ controlled crystallization, ${ }^{27,28}$ core-shell structures ${ }^{29}$ as well as avoiding high current transients during the coloration/ bleaching processes. Parallel work has demonstrated that $\mathrm{WO}_{3}$ films that have undergone severe degradation by harsh electrochemical cycling in a Li-ion-conducting electrolyte can be rejuvenated repeatedly by galvanostatic ${ }^{30,31}$ or potentiostatic ${ }^{32}$ treatments, and similar results have been obtained for 
electrochromic $\mathrm{TiO}_{2},{ }^{33} \mathrm{MoO}_{3},{ }^{34}$ and $\mathrm{NiO}^{35}$ Degradation is due to irreversible incorporation of $\mathrm{Li}$ ions in the $\mathrm{W}$ oxide film, and rejuvenation can be unambiguously related to electrochemically induced removal of these ions. ${ }^{36,37}$ Here we analyze another recently discovered approach towards stable electrochromic devices $^{38}$ and demonstrate that $\mathrm{W}$ oxide films can attain unprecedented durability via a simple and straight-forward potentiostatic pretreatment in a Li-ion-conducting electrolyte. Several analytical techniques were used to probe changes of the film and its backing during the potentiostatic treatment and provided compelling information on the origins of the improved durability.

\section{Experimental section}

\section{Thin film deposition}

Thin films of $\mathrm{WO}_{3}$ were prepared by reactive DC magnetron sputtering in a deposition system based on a Balzers UTT 400 unit. The target was a $5 \mathrm{~cm}$-diameter plate of tungsten (Plasmaterials) with $99.99 \%$ purity. The sputter system was evacuated to $6 \times 10^{-5}$ Pa before starting the deposition process, and the target was pre-sputtered in pure argon with a discharge power of $150 \mathrm{~W}$ for $3 \mathrm{~min}$ prior to sample preparation. Argon and oxygen, both of $99.997 \%$ purity, were then introduced through mass-flow controlled gas inlets. The $\mathrm{O}_{2} / \mathrm{Ar}$ ratio was set to 0.15 and the working pressure was $\sim 4 \mathrm{~Pa}$. Substrates were unheated $1 \times 5 \mathrm{~cm}^{2}$ glass plates coated with transparent and electrically conducting layers of $\mathrm{In}_{2} \mathrm{O}_{3}: \mathrm{Sn}$ (ITO) having a resistance of $60 \Omega$ per square. The target-substrate separation was $13 \mathrm{~cm}$. The substrate holder was rotated at $20 \mathrm{rpm}$ to ensure film uniformity. The discharge power during sample preparation was set to $230 \mathrm{~W}$, which yielded a deposition rate of $\sim 47$ $\mathrm{nm} \mathrm{min}{ }^{-1}$. Film thicknesses were $300 \pm 20 \mathrm{~nm}$ as determined $e x$ situ by surface profilometry using a Bruker DektakXT instrument.

\section{Electrochemical measurements and treatments}

Cyclic voltammetry and potentiostatic treatments were performed in an argon-filled glovebox, whose water content was below $\sim 0.5 \mathrm{ppm}$, by use of a Solartron 1286 Electrochemical Interface. Electrochemical impedance spectroscopy measurements were carried out by use of a BioLogic SP-200 potentiostat in the frequency range of $0.1 \mathrm{~Hz}$ to $10 \mathrm{kHz}$ with a $10 \mathrm{mV}$ amplitude AC signal. The electrochemical cell contained three electrodes with the $\mathrm{W}$ oxide film serving as working electrode and Li foils being counter and reference electrodes. The electrolyte was $1 \mathrm{M}$ lithium perchlorate $\left(\mathrm{LiClO}_{4}\right)$ dissolved in propylene carbonate $\left(\mathrm{C}_{4} \mathrm{H}_{6} \mathrm{O}, \mathrm{PC}\right)$. In situ optical properties were recorded, together with the electrochemical measurements, at a mid-luminous wavelength of $550 \mathrm{~nm}$ as well as in the 400$800 \mathrm{~nm}$ wavelength range with an Ocean Optics fiber-optic setup. The transmittance of the electrochemical cell filled with electrolyte was put to unity and used as reference.

As-deposited films were potentiostatically pretreated by immersing them in the electrolyte and applying a potential, with polarity such that positive ions were expelled from the sample, for several hours. Fig. 1 reports data on current density evolution and mid-luminous optical transmittance when a constant potential of $6.0 \mathrm{~V} v s . \mathrm{Li}^{2} \mathrm{Li}^{+}$was applied during $24 \mathrm{~h}$. The current density exhibits a rapid initial decline followed by a distinctive broad feature, occurring in the time span of 1-6 $\mathrm{h}$ and peaked at $\sim 4.23 \mathrm{~h}$, with a final asymptotic approach towards zero. The peak is conspicuously similar to current responses found in prior work of ours on potentiostatic rejuvenation and Li-ion-detrapping of degraded $\mathrm{WO}_{3}$ films at volt-

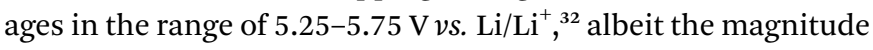
of the peak is larger in Fig. 1 than in the rejuvenation experiment. Clear similarities among data taken during potentiostatic pretreatment and film rejuvenation are apparent also from a "Cottrell plot" of current density multiplied by $t^{1 / 2} v s . \log (t)$, where $t$ is time (ESI, Fig. S1 $\dagger$ ). ${ }^{39}$ This plot displays not only a main peak after $\sim 4.57 \mathrm{~h}$ but also a broad feature centered at $\sim 5$ min. Such a two-peaked structure is consistent with our prior data $^{32}$ and deviations from a horizontal line highlight departures from purely diffusion-limited processes. The in situ optical transmittance at $550 \mathrm{~nm}$, also shown in Fig. 1, is almost featureless and a very shallow broad minimum after $\sim 10 \mathrm{~h}$ is probably not significant. Optical data for as-deposited and potentiostatically pretreated $\mathrm{WO}_{3}$ films will be discussed in more detail below.

\section{Materials analysis}

For all ex situ measurements, the films were removed from the glove box, rinsed in 2-propanol and dried with nitrogen to eliminate electrolyte residues. Structural characterization of $\mathrm{W}$ oxide films was performed with X-ray diffraction (XRD) using a Siemens D5000 instrument working with $\mathrm{Cu} \mathrm{K}_{\alpha}$ radiation. Surface structures were investigated by scanning electron microscopy (SEM) employing a Zeiss 1550 FEG Gemini instrument with an acceleration voltage of $5 \mathrm{kV}$.

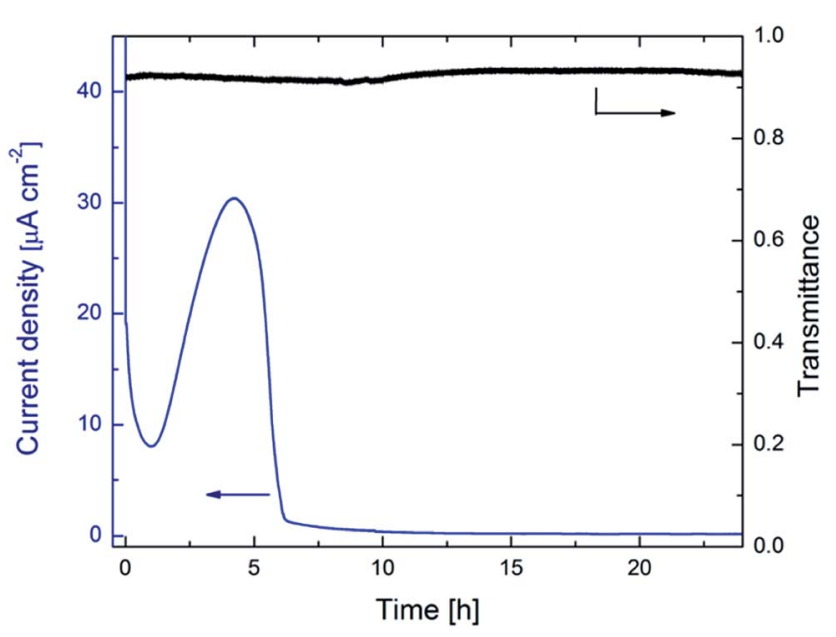

Fig. 1 Evolution of current density (left-hand scale) and optical transmittance at a wavelength of $550 \mathrm{~nm}$ (right-hand scale) for a 300 $\mathrm{nm}$-thick $\mathrm{WO}_{3}$ film immersed in $\mathrm{LiClO}_{4}-\mathrm{PC}$ and subjected to potentiostatic treatment at $6.0 \mathrm{~V}$ vs. $\mathrm{Li}^{\prime} / \mathrm{Li}^{+}$. Arrows indicate applicable vertical scale. 
X-ray photoemission spectroscopy (XPS) was conducted with a PHI Quantum 2000 Scanning ESCA Microprobe operating with monochromatic $\mathrm{Al} \mathrm{K}_{\alpha 1}$ radiation and having a beam diameter of $200 \mu \mathrm{m}$. Survey scans were taken for $0-1100 \mathrm{eV}$ with pass energy of $117.4 \mathrm{eV}$ and $1 \mathrm{eV}$ resolution. High-resolution scans were obtained with pass energy of $23.50 \mathrm{eV}$ and $0.025 \mathrm{eV}$ resolution. Sample charging was avoided via a neutralizer filament. Adventitious carbon, with its $1 \mathrm{~s}$ peak at $248.8 \mathrm{eV}$, was used to calibrate spectra and correct for peak shifts due to charging. Elemental depth profiles during sputter etching were obtained with pass energy of $224.00 \mathrm{eV}$ and $0.50 \mathrm{eV}$ resolution.

Additional elemental depth profiles were obtained with timeof-flight elastic recoil detection analysis (ToF-ERDA), using 36 $\mathrm{MeV}^{127} \mathrm{I}^{8+}$ primary ions, at the Tandem Accelerator Laboratory of Uppsala University. Technical details pertinent to the set-up are given in the literature. ${ }^{40}$ Time-of-flight/energy coincidence data were transformed to concentration profiles by use of the software CONTES. ${ }^{41}$ Elemental contents were also determined by Rutherford backscattering spectrometry (RBS) at the Uppsala Tandem Laboratory, using $2 \mathrm{MeV}^{4} \mathrm{He}$ ions backscattered at an angle of $170^{\circ}$. RBS spectra were fitted to a model for the filmsubstrate system via the SIMNRA program. ${ }^{42}$

Raman spectra were recorded with an inVia Reflex confocal Raman microscope (Renishaw, Gloucestershire, UK), using a 100× objective lens and $532 \mathrm{~nm}$-wavelength laser and $2400 \mathrm{l} \mathrm{mm}^{-1}$ grating, in the wavenumber range of $100-2000 \mathrm{~cm}^{-1}$. Attenuated total reflectance Fourier transform infrared (ATR-FTIR) spectra were taken with a Bruker IFS 66v/S FTIR spectrometer equipped with a PIKE WeeMax III single reflection electro-ATR and a liquidnitrogen-cooled $\mathrm{HgCdTe}$ detector. The spectroscopic measurements were performed in air with $4 \mathrm{~cm}^{-1}$ resolution.

Further details on thin-film preparation, experimental procedures and sample analysis can be found in earlier papers of ours. ${ }^{30,33,36}$

\section{Results}

\section{Cyclic charge exchange and electrochromism}

Fig. 2 presents our key electrochemical results and demonstrates that potentiostatic pretreatment of $\mathrm{WO}_{3}$ thin films gives a striking improvement of the cyclic charge exchange. Fig. 2a and $a^{\prime}$ show cyclic voltammetry (CV) data for a potential window as wide as $1.5-4.0 \mathrm{~V} v s . \mathrm{Li} / \mathrm{Li}^{+}$and at a sweep rate of $20 \mathrm{mV} \mathrm{s}^{-1}$ for, respectively, a film in as-deposited state and after potentiostatic pretreatment at $6.0 \mathrm{~V} v s$. $\mathrm{Li} / \mathrm{Li}^{+}$. Considering first the asdeposited film (Fig. 2a), it is apparent that rapid degradation occurs during 40 harsh CV cycles, which is consistent with earlier results. ${ }^{30,36}$ The potentiostatically pretreated film shows much better durability, and the $\mathrm{CV}$ data are almost cycleindependent (Fig. 2a'). The CV data are further analyzed in Fig. $2 \mathrm{~b}$ and $\mathrm{b}^{\prime}$ which show data on inserted $\left(Q_{\text {inserted }}<0\right)$ and
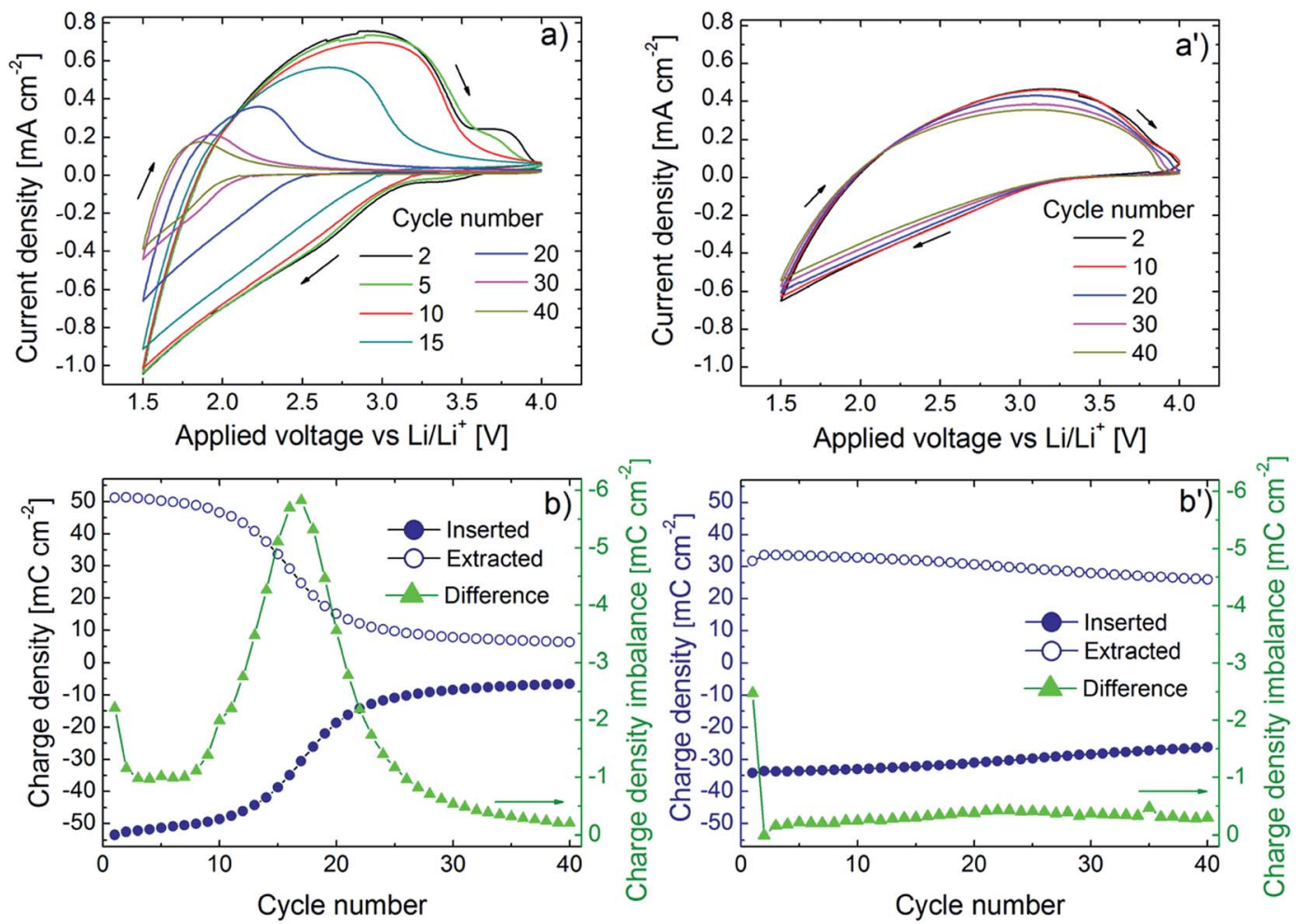

Fig. 2 Electrochemical data for $\sim 300 \mathrm{~nm}$-thick $\mathrm{WO}_{3}$ films immersed in $\mathrm{LiClO}_{4}-\mathrm{PC}$. Panels (a) and (b) refer to as-deposited films and panels (a') and $\left(b^{\prime}\right)$ to films that have been potentiostatically pretreated at $6.0 \mathrm{~V} \mathrm{vs}$. Li/Li ${ }^{+}$for $24 \mathrm{~h}$. Cyclic voltammograms in panels (a) and ( $\left.a^{\prime}\right)$ were recorded in $\mathrm{LiClO}_{4}-\mathrm{PC}$ after the indicated numbers of cycles at a sweep rate of $20 \mathrm{mV} \mathrm{s}^{-1}$; arrows indicate sweep direction. Inserted and extracted charge density, shown in panels (b) and ( $\left.b^{\prime}\right)$, were obtained from the data in panels ( $a$ ) and $\left(a^{\prime}\right)$; panels (b) and ( $\left.b^{\prime}\right)$ also display difference in absolute value of charge density for successive charge insertions and extractions (individual data points are joined by straight lines for clarity). 
extracted $\left(Q_{\text {extracted }}>0\right)$ charge density as well as on charge imbalance $\delta Q$ between successive insertion and extraction cycles, given by $\delta Q=\left|Q_{\text {inserted }}+Q_{\text {extracted }}\right|$. Initially, the asdeposited film has larger values of $Q_{\text {inserted }}$ and $Q_{\text {extracted }}$ than the potentiostatically pretreated one. However, the as-deposited film shows rapid declines in $Q_{\text {inserted }}$ and $Q_{\text {extracted }}$ upon CV cycling and the change is most pronounced around the $15^{\text {th }}$ cycle (Fig. 2b). The potentiostatically pretreated film, on the other hand, displays much slower drops of $Q_{\text {inserted }}$ and $Q_{\text {extracted }}$ and the charge exchange (i.e., the average of $Q_{\text {inserted }}$ and $Q_{\text {extracted }}$ ) becomes larger than for the as-deposited film after $\sim 15 \mathrm{CV}$ cycles. Furthermore, there is no clear peak in $\delta Q$ for the pretreated film (Fig. 2b').

Electrochromism is intimately connected with charge insertion/extraction, and optical transmittance modulation mirrors charge exchange. Fig. 3a and $a^{\prime}$ show mid-luminous transmittance for a $\mathrm{WO}_{3}$ film in as-deposited state and after potentiostatic pretreatment. The difference between the two sets of data is striking: the as-deposited film loses its transmittance modulation during the initial CV cycling in a fashion consistent with the earlier shown decline of charge exchange (Fig. 3a) whereas the potentiostatically pretreated film retains its electrochromism with only a minor deterioration of the optical modulation (Fig. 3a'). The effect of the potentiostatic pretreatment is manifested also in spectral optical data for the 400-780 nm wavelength range as seen in Fig. 3b and $b^{\prime}$. Once again, it is evident that the electrochromism is rapidly lost upon CV cycling of the as-deposited film whereas the potentiostatically pretreated film has essentially cycling-independent optical performance. The optical properties of the as-deposited films agree fully with our earlier results..$^{25,30-32,36}$

We also considered the role of potentiostatic pretreatment on the coloration efficiency (CE), which is a technically important property governing the efficiency of an electrochromic device and should be maximized for smart windows. The CE is given by $\ln \left(T_{\text {bleached }} / T_{\text {colored }}\right) / \Delta Q$, where $T_{\text {bleached }}$ and $T_{\text {colored }}$ are the transmittance of the film in its bleached and colored states, respectively, and $\Delta Q$ is the absolute value of $Q_{\text {inserted }}$. As seen in Fig. $\mathrm{S} 2, \uparrow$ the CE pertaining to a wavelength of $550 \mathrm{~nm}$ declines monotonically for the as-deposited film whereas it varies smoothly between 60 and $70 \mathrm{~cm}^{2} \mathrm{C}^{-1}$ for the potentiostatically pretreated film and attains its largest values at the approach of $40 \mathrm{CV}$ cycles.

\section{Characterization of as-deposited and potentiostatically pretreated films}

A wide range of characterization techniques was used in order to shed light on the crucial differences between as-deposited and potentiostatically pretreated samples. Structural characterization by XRD, reported in Fig. $\mathrm{S} 3, \dagger$ showed nothing but diffraction peaks due to the underlying ITO layer, implying that both types of $\mathrm{WO}_{3}$ films were amorphous. Morphological
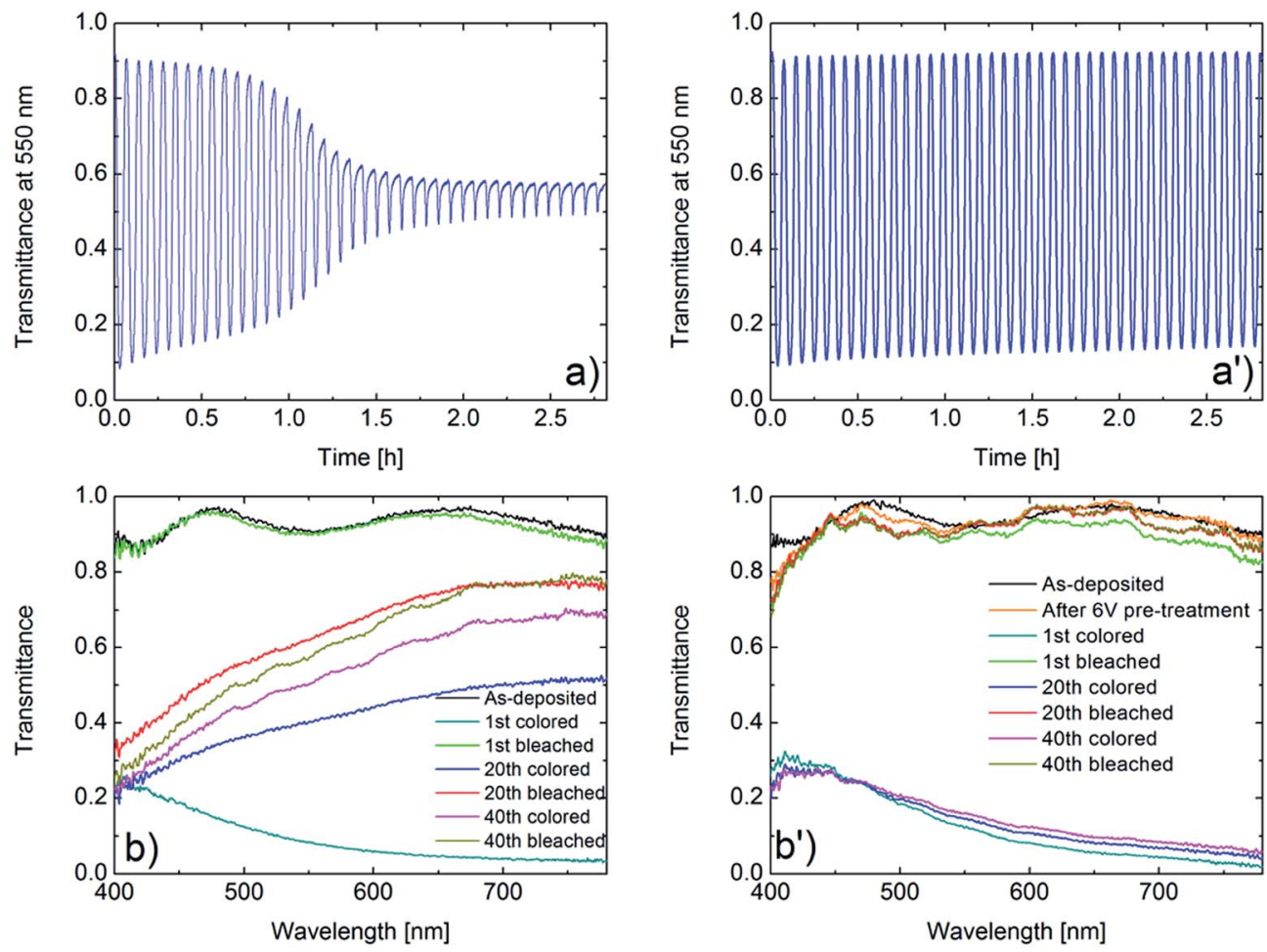

Fig. 3 Optical data for $\sim 300 \mathrm{~nm}$-thick $\mathrm{WO}_{3}$ films immersed in $\mathrm{LiClO}_{4}-\mathrm{PC}$. Panels (a) and (b) refer to as-deposited films and panels ( $\mathrm{a}^{\prime}$ ) and ( $\mathrm{b}^{\prime}$ ) to films that have been potentiostatically pretreated in $\mathrm{LiClO}_{4}-\mathrm{PC}$ at $6.0 \mathrm{~V}$ vs. $\mathrm{Li}^{\prime} \mathrm{Li}^{+}$for $24 \mathrm{~h}$. Optical transmittance modulation at a wavelength of $550 \mathrm{~nm}$ is shown in panels (a) and $\left(a^{\prime}\right)$ and spectral optical transmittance after the stated number of ion insertion (coloring) and ion extraction (bleaching) cycles is shown in panels $(b)$ and $\left(b^{\prime}\right)$; the optical data were taken in conjunction with the electrochemical measurements (some spectral data are partly overlapping). 

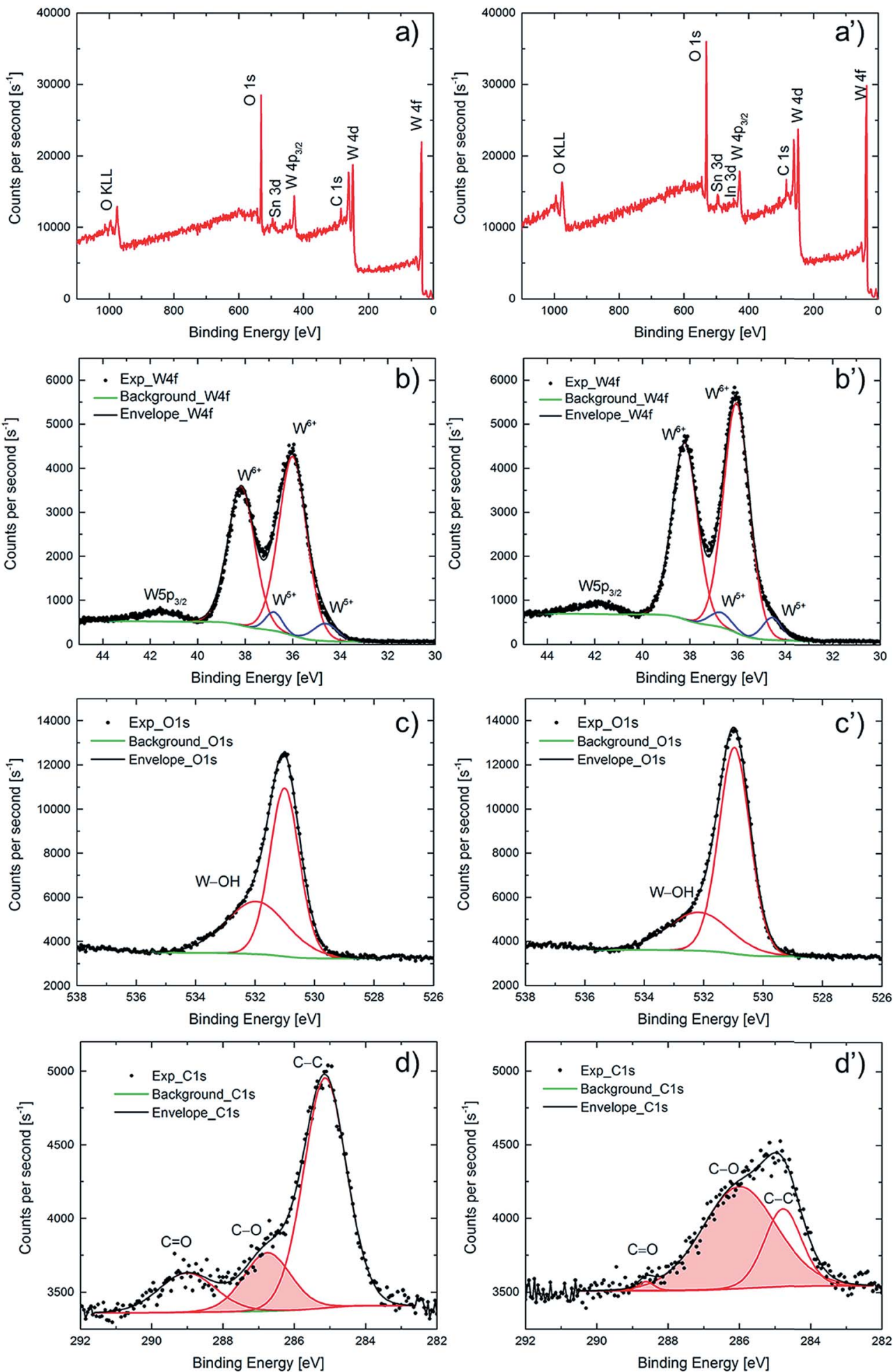

Fig. 4 XPS count rate as a function of binding energy for $\sim 300 \mathrm{~nm}$-thick $\mathrm{WO}_{3}$ films. Panels (a) and (a') represent survey scans of a film in (a) asdeposited state and $\left(\mathrm{a}^{\prime}\right)$ after potentiostatic pretreatment in $\mathrm{LiClO}_{4}-\mathrm{PC}$ at $6.0 \mathrm{~V}$ vs. $\mathrm{Li} / \mathrm{Li}^{+}$for $24 \mathrm{~h}$. Panels $(\mathrm{b})$ and $\left(\mathrm{b}^{\prime}\right)$ are corresponding data specifically for the energy range pertaining to $W 4 f$ (and $W 5 p_{3 / 2}$ at $\sim 42 \mathrm{eV}$ ), panels (c) and ( $c^{\prime}$ ) refer to $O 1$ s and panels (d) and ( $d^{\prime}$ ) refer to $C 1 \mathrm{~s}$ electrons. Electronic transitions are indicated in panels (a) and ( $\left.a^{\prime}\right)$, charge states are noted in panels (b) and ( $\left.b^{\prime}\right)$, and shaded bell-shaped areas in panels (d) and ( $d^{\prime}$ ) signify the stated chemical bonds. Dots represent measurements and curves are fittings, as described in the main text. Bottom curves in panels ( $b$ and $\left.b^{\prime}\right)$, ( $c$ and $c^{\prime}$ ) and ( $d$ and $d^{\prime}$ ) mark backgrounds. 
characterization was performed by SEM; Fig. S4† depicts micrographs of the surfaces of the two kinds of films and indicates that they are composed of aggregated $\sim 10 \mathrm{~nm}$-size grains with interspersed cracks and crevices; no significant difference can be associated with the potentiostatic pretreatment. The images are consistent with those reported before for similarly prepared $\mathrm{WO}_{3}$ films. ${ }^{25}$

XPS was used to determine elemental compositions for the films' surfaces, as well as depth profiles through the $\mathrm{WO}_{3}$ films down into the underlying ITO-coated glass substrate, in order to document differences between as-deposited and potentiostatically pretreated films. XPS survey scans are displayed in Fig. 4a and $\mathrm{a}^{\prime}$ for the surfaces of the two types of films and show features due to carbon, oxygen, tungsten and tin. Features due to indium on the surface were clearly seen only for the pretreated film. Corresponding atomic concentrations are reported in Table 1, which indicates that the $\mathrm{WO}_{3}$ film remains stoichiometric after the pretreatment. Moreover, it is found that the carbon concentration is decreased by about $20 \%$ as a result of the pretreatment and, interestingly, that the In concentration concurrently is more than doubled-from $\sim 0.3$ to $\sim 0.7$ at $\%-$ signaling that In diffusion through the $\mathrm{WO}_{3}$ film is promoted by the potentiostatic pretreatment.

High-resolution XPS spectra pertaining to spin-orbit split W $4 \mathrm{f}$ electrons are reported in Fig. $4 \mathrm{~b}$ and $\mathrm{b}^{\prime}$. The binding energies of the $\mathrm{W} 4 \mathrm{f}_{5 / 2}$ and $\mathrm{W} 4 \mathrm{f}_{7 / 2}$ peak doublet are close to the values reported for $\mathrm{WO}_{3} \cdot{ }^{43-45}$ Further quantification of the charge states of the tungsten atoms was accomplished by peak deconvolution (Fig. $4 \mathrm{~b}$ and $\mathrm{b}^{\prime}$ ). Constraining the relative $4 \mathrm{f}_{5 / 2}$ and $4 \mathrm{f}_{7 / 2}$ peak areas to $3 / 4$ and fitting the experimental data to Gaussian-Lorentzian peaks, the $\mathrm{W}^{5+} / \mathrm{W}^{6+}$ ratio was found to be $8 \%$ and $7 \%$ for as-deposited and potentiostatically pretreated films, respectively, showing that both films were predominantly comprised of stoichiometric $\mathrm{WO}_{3}$. The small feature at a binding energy of $\sim 42 \mathrm{eV}$ is the $5 \mathrm{p}_{3 / 2}$ peak characteristic of $\mathrm{WO}_{3} \cdot{ }^{44}$ The $\mathrm{O} 1 \mathrm{~s}$ peak occurs at $531.0 \mathrm{eV}$ (Fig. 4c and $\mathrm{c}^{\prime}$ ) as expected for $\mathrm{WO}_{3}$ and exhibits a small shoulder at $532.1 \mathrm{eV}$ due to hydroxylation $(\mathrm{W}-\mathrm{OH}) .{ }^{45}$
Importantly, it was possible to document a significant difference in the energy-resolved XPS spectra pertaining to $\mathrm{C} 1 \mathrm{~s}$ electrons (Fig. $4 \mathrm{~d}$ and $\mathrm{d}^{\prime}$ ) for as-deposited and potentiostatically pretreated films. There is general agreement in the literature on the assignment of the peaks in the $\mathrm{C} 1 \mathrm{~s}$ region, ${ }^{46-48}$ and the $\mathrm{C} 1 \mathrm{~s}$ spectra of both films could be deconvoluted into contributions from $\mathrm{C}=\mathrm{O}$ at $288.7 \mathrm{eV}, \mathrm{C}-\mathrm{O}$ at $286.0 \mathrm{eV}$ and $\mathrm{C}-\mathrm{C}$ at $284.8 \mathrm{eV}$. The $\mathrm{C}$ 1s signal from the as-deposited film is due mainly to adventitious aliphatic carbon contaminants with characteristic binding energy of $284.8 \mathrm{eV}$ (used for internal energy calibration) due to $\mathrm{C}-\mathrm{C}$ bonds ( $67 \%$ of the total integrated $\mathrm{O} 1 \mathrm{~s}$ peak area). However, after the potentiostatic pretreatment, the relative magnitudes of the three bands were markedly different. Thus the $\mathrm{C}-\mathrm{O}$-derived peak at $286.0 \mathrm{eV}$ became dominant $(69 \%$ of the total integrated $\mathrm{O} 1 \mathrm{~s}$ peak area) whereas the $\mathrm{C}=\mathrm{O}$-derived peak at $288.7 \mathrm{eV}$ shrank (peak area decreased from 15\% to less than $3 \%$ ). These results are consistent with the formation of a carbon-containing solid-electrolyte interfacial layer on the surface of the $\mathrm{WO}_{3}$ film comprising $\mathrm{C}-\mathrm{O}$ species due to reactions with the electrolyte.

It should be noted that the carbonate-like layer existed only on the films' surfaces and XPS depth profile data, reported in the insets of Fig. 5, indicate that the $\mathrm{C} 1$ s atomic concentrations were low for as-deposited and potentiostatically pretreated $\mathrm{WO}_{3}$ films. The XPS data also showed clear signals due to $\mathrm{W}$ in $\mathrm{WO}_{3}$, In and $\mathrm{Sn}$ from ITO, Si from glass, and $\mathrm{O}$ from $\mathrm{WO}_{3}$, ITO and glass. Clear evidence for $\mathrm{C}$ was found only at sputter times less than $0.5 \mathrm{~min}$ and occurred along with increased $\mathrm{O}$ and decreased $\mathrm{W}$ signals. As shown in Fig. $5 \mathrm{a}$, the $\mathrm{WO}_{3} / \mathrm{ITO}$ interface of the as-deposited film was quite distinct, and the signal due to $\mathrm{W}$ started to decrease at the same time as the In, Sn and O signals from ITO increased steeply after a sputter time of $\sim 73$ min. The intensity due to In was very large and exhibited a maximum after $\sim 85 \mathrm{~min}$, which was consistent with the location of the ITO/glass interface. Later, as the sputter-etch process continued, the signals from In and Sn decreased and the Si signal began to increase, as expected from ITO deposited

Table 1 Core-hole binding energies and atomic concentrations obtained from XPS data

\begin{tabular}{|c|c|c|c|c|}
\hline Atomic orbital & As-deposited & $\begin{array}{l}\text { Potentiostatically } \\
\text { pretreated }\end{array}$ & As-deposited & $\begin{array}{l}\text { Potentiostatically } \\
\text { pretreated }\end{array}$ \\
\hline C $1 \mathrm{~s}$ & 284.8 & 284.8 & 29.6 & 23.2 \\
\hline $\mathrm{O} 1 \mathrm{~s}$ & 531.0 & 531.0 & 52.3 & 56.6 \\
\hline W 4f & & & 17.1 & 18.5 \\
\hline $\mathrm{W}^{6+} 4 \mathrm{f}_{5 / 2}$ & 38.2 & 38.1 & & \\
\hline $4 f_{7 / 2}$ & 36.1 & 36.0 & & \\
\hline In $3 d$ & & & 0.3 & 0.7 \\
\hline In $3 d_{3 / 2}$ & - & 452.5 & & \\
\hline $3 d_{5 / 2}$ & - & 445.2 & & \\
\hline Sn $3 d$ & & & 1.0 & 0.7 \\
\hline
\end{tabular}



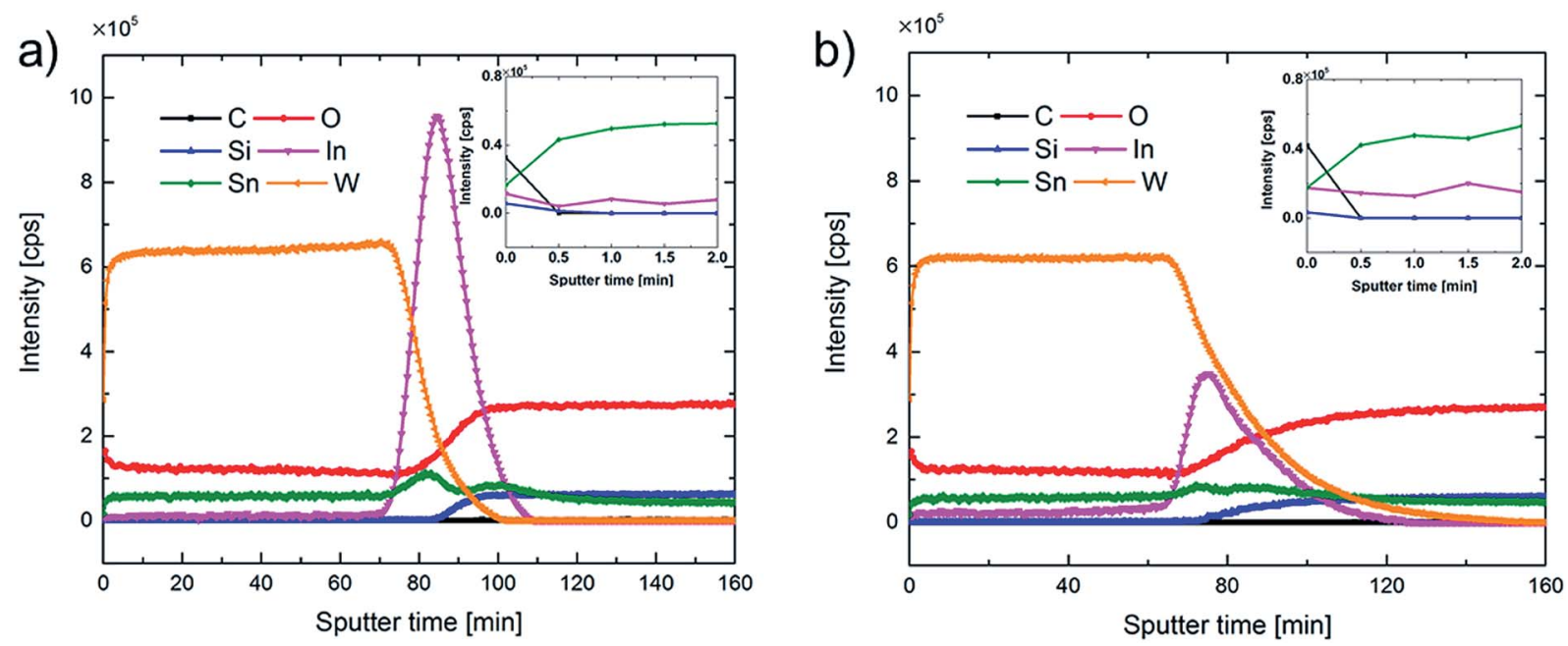

Fig. 5 XPS depth profiles for $300 \mathrm{~nm}$-thick $\mathrm{WO}_{3}$ films, backed by ITO-coated glass, in (a) as-deposited state and (b) after potentiostatic pretreatment in $\mathrm{LiClO}_{4}-\mathrm{PC}$ at $6.0 \mathrm{~V}$ vs. Li/Li ${ }^{+}$for $24 \mathrm{~h}$. Insets show intensities due to the shown elements at the beginning of the sputter process.

onto glass. In contrast, after potentiostatic pretreatment (Fig. $5 \mathrm{~b}$ ), the intensities of the In and Sn signals were drastically reduced, indicating degradation of the ITO layer, and the $\mathrm{WO}_{3} /$ ITO and ITO/glass interfaces became broadened. The In concentration profile shows that In penetrates into $\mathrm{WO}_{3}$ and also partly mixes with the glass along with $\mathrm{W}$ after pretreatment. The degradation of the ITO layer increases its resistance as clearly shown by electrochemical impedance spectroscopy (Fig. S5 $†$ ). Specifically, the high-frequency resistance associated with ITO grows by almost a factor three after the pretreatment.

Complementary elemental depth profiling was carried out with ToF-ERDA and RBS, and Fig. S6 $\dagger$ shows ERDA data for asdeposited and potentiostatically pretreated $\mathrm{WO}_{3}$ films. The atomic fractions for $\mathrm{W}$ and $\mathrm{O}$ are consistent with $\mathrm{WO}_{3}$ stoichiometry, the hydrogen content is $\sim 10$ at $\%$ most likely emanating from $\mathrm{OH}^{-}$due to surface contamination, and there are trace amounts of nitrogen and carbon. A signal due to (In + Sn) was detected, although In and Sn could not be resolved individually; moreover the depth resolution of ERDA for these heavy subsurface species is poor. The composition profile of the $\mathrm{WO}_{3}$ layer for both samples is essentially depth-independent over the cross-sections as apparent from both ERDA data in Fig. S6 $\dagger$ and the plateau exhibited by the signal due to $\mathrm{W}$ in the RBS spectra in Fig. 6 . The latter figure shows experimental and simulated RBS data for asdeposited and potentiostatically pretreated $\mathrm{WO}_{3}$ films. The atomic masses of In and Sn are too close to allow separation of the signals from the individual elements. However, the data show clear evidence that the amount of (In + Sn) was reduced after potentiostatic pretreatment, which is consistent with the XPS depth profile data. Furthermore, the less deep minimum between the (In $+\mathrm{Sn})$ and $\mathrm{W}$ areas, as well as the increased spread of the data points in the area associated with $\mathrm{W}$, indicate that In atoms
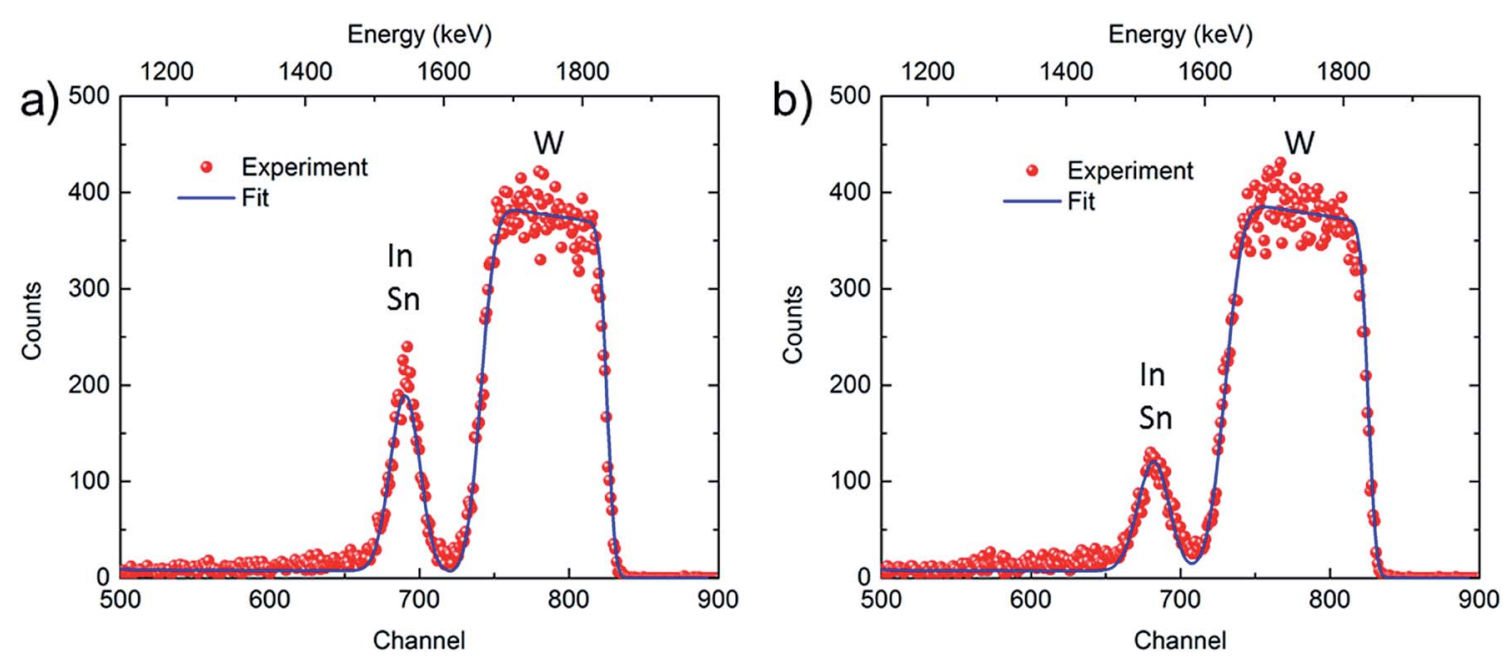

Fig. 6 Experimental and simulated RBS spectra for a $300 \mathrm{~nm}$-thick $\mathrm{WO}_{3}$ film in (a) as-deposited state and (b) after potentiostatic pretreatment in $\mathrm{LiClO}_{4}-\mathrm{PC}$ at $6.0 \mathrm{~V}$ vs. $\mathrm{Li} / \mathrm{Li}^{+}$for $24 \mathrm{~h}$. Elemental compositions were determined by fitting experimental results (red dots) and simulated data (blue curves). 

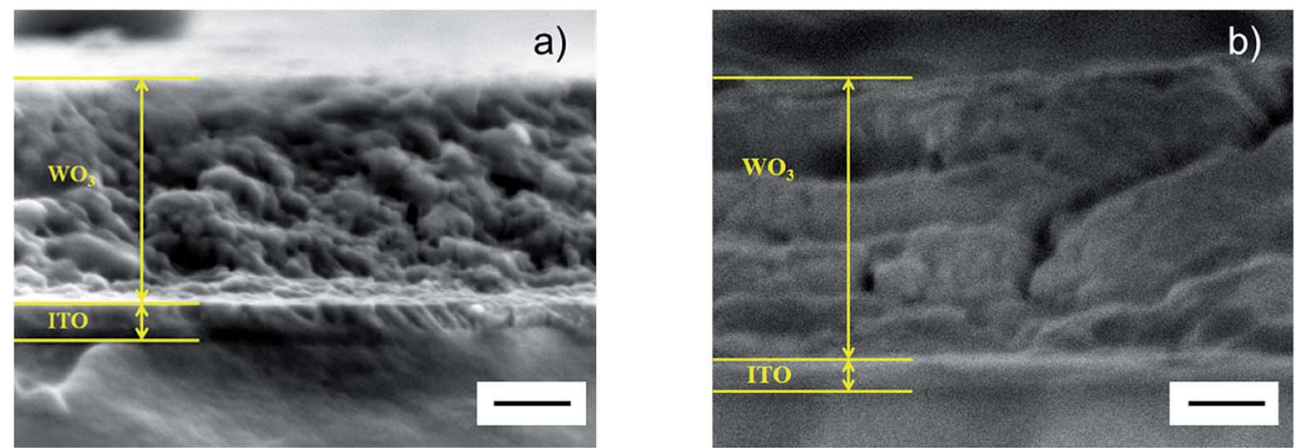

Fig. 7 SEM cross-sectional images of a $\sim 300 \mathrm{~nm}$-thick $\mathrm{WO}_{3}$ film, backed by ITO-coated glass, in (a) as-deposited state and (b) after potentiostatic pretreatment in $\mathrm{LiClO}_{4}-\mathrm{PC}$ at $6.0 \mathrm{~V}$ vs. $\mathrm{Li}_{/} \mathrm{Li}^{+}$for $24 \mathrm{~h}$. Scale bars are $100 \mathrm{~nm}$.

are able to penetrate into the $\mathrm{WO}_{3}$ layer during the pretreatment, as was also found from the XPS depth profile data.

SEM was used to acquire direct information on the films' cross-sections, and the data shown in Fig. 7 document structural modifications after the potentiostatic pretreatment. The as-deposited film exhibits two clearly visible layers: an upper porous film of $\mathrm{WO}_{3}$ with a thickness of $\sim 320 \mathrm{~nm}$ and a lower dense layer of ITO with a thickness of $\sim 50 \mathrm{~nm}$. After the pretreatment, the $\mathrm{WO}_{3}$ layer became significantly thicker; the thickness was $\sim 380 \mathrm{~nm}$, which may be due to a more porous structure developed during the In-intermixing process as well as to the carbonaceous interfacial layer formed on the surface of the $\mathrm{WO}_{3}$ film as indicated by the C $1 \mathrm{~s}$ XPS spectra. Furthermore, the ITO layer became thinner and had a thickness of $\sim 37 \mathrm{~nm}$.

Vibrational spectroscopy was applied in order to further elucidate changes of the films during potentiostatic pretreatment and degradation, and complementary results were acquired for the ITO layer. Fig. 8a shows Raman spectra; the broad peak at a wavenumber of $770 \mathrm{~cm}^{-1}$ corresponds to symmetric and asymmetric $\nu(\mathrm{O}-\mathrm{W}-\mathrm{O})$ stretching modes, while the peak at $950 \mathrm{~cm}^{-1}$ can be assigned either to the $\nu(\mathrm{W}=\mathrm{O})$ stretching modes due to terminal oxygen atoms ${ }^{49-52}$ or to surface carbonates, ${ }^{53}$ or to combinations of these. After potentiostatic pretreatment of the uncycled film at $6.0 \mathrm{~V} v s . \mathrm{Li} / \mathrm{Li}^{+}$, the Raman spectrum was similar to the one for the as-deposited film. However, an up-shift and broadening of the band at $950 \mathrm{~cm}^{-1}$ indicate a higher carbonate content after pretreatment. ${ }^{53}$ Notably, the Raman spectrum of the pretreated film did not change significantly after 40 harsh CV cycles. Hence the data provide clear evidence that the $\mathrm{O}-\mathrm{W}^{6+}-\mathrm{O}$ and $\mathrm{W}^{6+}=\mathrm{O}$ bonds do not undergo significant alterations during the potentiostatic pretreatment and that deposited carboxylate/bicarbonate species are removed.

Analogous data taken by ATR-FTIR spectroscopy are reported in Fig. $8 \mathrm{~b}$ with the aim to further establish carbonate formation at the electrolyte/film interface; it should be noted that ATRFTIR spectroscopy is a more sensitive technique than Raman spectroscopy for these surface species. The as-deposited film showed a peak at $\sim 900 \mathrm{~cm}^{-1}$ corresponding to $\nu(\mathrm{W}=\mathrm{O})$ stretching vibrations and increased absorbance at wavenumbers below $\sim 800 \mathrm{~cm}^{-1}$ due to $\nu(\mathrm{O}-\mathrm{W}-\mathrm{O})$ vibrational modes. ${ }^{49,54}$ The $\nu(\mathrm{W}=\mathrm{O})$ peak became less distinct after electrochemical cycling. After the potentiostatic pretreatment, the absorbance of the film increased markedly and two peaks,
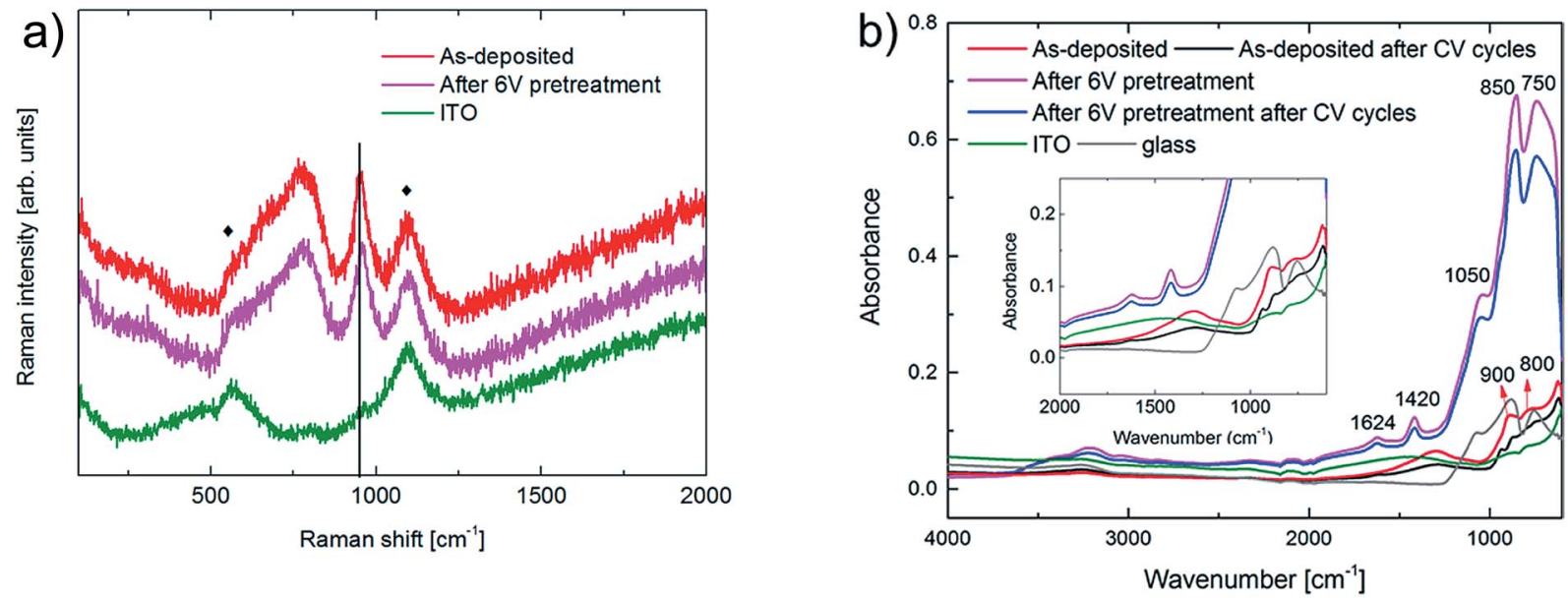

Fig. 8 (a) Raman and (b) ATR-FTIR spectra for $\sim 300 \mathrm{~nm}$-thick $\mathrm{WO}_{3}$ films in the indicated states, for an ITO layer and for glass. CV denotes cyclic voltammetry, and diamonds in panel (a) refer to features due to ITO. Inset in panel (b) shows spectra confined to the $600-2000 \mathrm{~cm}^{-1}$ wavenumber range. The black line in (a) is drawn to show a small red-shift of the peak around $950 \mathrm{~cm}^{-1}$ after $6 \mathrm{~V}$ pretreatment. 
associated with the glass substrate, emerged at $850 \mathrm{~cm}^{-1}$ and $750 \mathrm{~cm}^{-1}$. The appearance of these peaks may be attributed to a combination of decreased ITO thickness, deduced from SEM, and reduced extinction coefficient of the ITO layer due to lowered In concentration, as evidenced by In inter-diffusion into the $\mathrm{WO}_{3}$ film. The shoulder at $\sim 1050 \mathrm{~cm}^{-1}$ can be attributed to the TO phonon of the glass. Potentiostatic pretreatment at $6.0 \mathrm{~V}$ vs. $\mathrm{Li} / \mathrm{Li}^{+}$yields a peak at $1420 \mathrm{~cm}^{-1}$ which corresponds to $\mathrm{C}-\mathrm{O}$ symmetric stretching vibrations of carbonates deposited on the $\mathrm{WO}_{3}$ surface. ${ }^{55}$ Water appears in the $\mathrm{WO}_{3}$ films as evidenced by the peaks at $1624 \mathrm{~cm}^{-1}$ due to $\delta(\mathrm{H}-\mathrm{O}-\mathrm{H})$ vibrations and the broad band between 3200 and $3500 \mathrm{~cm}^{-1}$ due to $\nu(\mathrm{O}-\mathrm{H})$. Furthermore, after the pretreated film had undergone harsh electrochemical cycling it displayed almost the same ATR-FTIR spectrum as the one before the cycling thus indicating that there are no major changes of the film during the CV cycling after the pretreatment.

\section{Discussion}

This section attempts to consolidate our experimental results into a coherent picture describing the effects of the electrochemical pretreatment on the properties of the electrochromic films and especially on their durability. We first consider the influence of the pretreatment procedure. In preliminary measurements we applied high potentials, in an interval around $6.0 \mathrm{~V}$ vs. $\mathrm{Li} / \mathrm{Li}^{+}$, to as-deposited $\mathrm{WO}_{3}$ films. The voltage window for achieving durability enhancement was found to be very narrow: $5.75 \mathrm{~V}$ vs. $\mathrm{Li}^{2} \mathrm{Li}^{+}$was not sufficient whereas $6.25 \mathrm{~V}$ vs. $\mathrm{Li} / \mathrm{Li}^{+}$led to yellowish coloration of the electrolyte which indicated severe degradation. The origin of the current peak at $\sim 4.23 \mathrm{~h}$ in Fig. 1 is not entirely clear, although it is similar to a peak due to extraction of trapped Li ions during rejuvenation treatments, as mentioned above. Hence the peak seen in the present experiment is probably resulting from an ion-diffusionrelated current, which could be due to In and Sn from the degradation of the ITO layer, as indicated in the XPS and RBS data. It is indeed known that ITO dissolves at high applied potentials in aqueous electrolytes, ${ }^{56}$ and a similar process is likely to occur in a $\mathrm{LiClO}_{4}-\mathrm{PC}$ electrolyte. In our case, however, the dissolution is partially hindered by the overlying $\mathrm{WO}_{3}$ layer so that inter-diffusion takes place among In, Sn and W species. Another contribution to the current observed during the potentiostatic pretreatment could ensue from side reactions in the electrolyte. It is known that the oxidation of propylene carbonate starts already at $4.5 \mathrm{~V} v s$. $\mathrm{Li} / \mathrm{Li}^{+}$and is expected to be significant at $6.0 \mathrm{~V} v s$. $\mathrm{Li} / \mathrm{Li}^{+}{ }^{57}$ Electrolyte degradation could also be the cause of the carbonaceous layer on the tungsten oxide, that was detected by XPS and ATR-FTIR. Such a layer would be kindred to solid-electrolyte interphases (SEIs) which are well-known in battery technology. The formation of organics-containing SEIs on battery cathodes at high potentials is firmly established experimentally but the details of their formation, and even their composition, are not well understood. $^{\mathbf{5 8}}$

Several structural and compositional changes occur in the $\mathrm{WO}_{3}$ film during the potentiostatic pretreatment as evidenced by a number of characterization techniques. A decrease of the $($ In + Sn) content in the ITO layer after pretreatment was documented by both XPS and RBS. Evidently the ITO dissolves when subjected to potentials of the order of $6.0 \mathrm{~V} v s . \mathrm{Li} / \mathrm{Li}^{+}{ }^{56}$ and $\left(\mathrm{In}+\mathrm{Sn}\right.$ ) diffuses into the $\mathrm{WO}_{3}$ layer so that intermixing of the metallic constituents takes place. Concurrently there is a decrease of the ITO thickness, as evidenced by SEM, which leads to a higher resistance of the ITO layer as seen from impedance spectroscopy (Fig. S5†). In this context, we note recent work ${ }^{59}$ on the electrochemical properties of $\mathrm{WO}_{3}$ films backed by glass pre-coated with ITO as well as by indiumtungsten oxide (IWO) wherein it was reported that the maximum current density (oxidation peak) in the CV data shifted slightly towards higher potential upon extended cycling for samples containing IWO. This observation is consistent with our results in Fig. $2 \mathrm{a}^{\prime}$ and may lend some support to the interdiffusion of $\mathrm{W}$ and In observed by XPS (Fig. 5). Another conspicuous structural change is related to carbonaceous surface layers, and electrochemical cycling of as-deposited $\mathrm{WO}_{3}$ films yielded carbonate deposits as indicated by $\mathrm{C}-\mathrm{O}$ bonds observed by XPS and ATR-FTIR. The XPS depth profile (Fig. 5) showed that this surface layer is very thin; a rough estimate yields a thickness less than $5 \mathrm{~nm}$ (based on the sputter rate for the metal atoms, viz. $\sim 4 \mathrm{~nm} \mathrm{~min}^{-1}$ ).

It is not possible at this stage to formulate a detailed model on how the mentioned structural and compositional changes are related to the enhanced stability during electrochemical cycling. However, some remarks on possible contributing factors can be made. The mixing of In, and to a smaller extent $\mathrm{Sn}$, into the $\mathrm{WO}_{3}$ layer might produce effects that are similar to those of $\mathrm{Ti}$, which has a well-established ability to enhance the electrochemical stability of $\mathrm{WO}_{3}$ films ${ }^{17-22}$ presumably by stabilizing an amorphous structure. Evidence in favor of $\mathrm{Sn}$ addition to $\mathrm{WO}_{3}$ giving somewhat improved cycling durability can in fact be found in prior work on sol-gel-deposited films. ${ }^{\mathbf{6 0}}$ Furthermore, the increased resistance of the ITO after pretreatment leads to a larger potential drop over the ITO film, thereby making the electrochemical cycling less harsh. A denser $\mathrm{WO}_{3}$ film is sometimes associated with higher electrochemical stability, ${ }^{27}$ but SEM showed a thickness increase after pretreatment which is sufficiently large that it is very unlikely to be due solely to the carbonaceous layer. Clearly, the protecting influence of the carbonaceous layer deserves attention in future studies.

To sum up, the increased electrochemical stability of $\mathrm{WO}_{3}$ films after pretreatment at high potential is likely due to a number of contributing effects: In (and Sn) intermixing in $\mathrm{WO}_{3}$, increased ITO resistance, and formation of a carbonaceous solid-electrolyte interface. The detailed characterization of as-deposited and potentiostatically pretreated films, presented in the present work, has narrowed down the range of possible causes for the electrochemical stability and has pointed out some directions for further studies.

\section{Conclusions}

The key result of the present work is that sputter deposited electrochromic tungsten oxide thin films are able to reach 
unprecedented electrochemical durability by potentiostatic pretreatment in $\mathrm{LiClO}_{4}-\mathrm{PC}$ at $6.0 \mathrm{~V}$ vs. $\mathrm{Li} / \mathrm{Li}^{+}$for several hours. These films maintain excellent optical modulation during repeated charge insertion/extraction, whereas as-deposited films of the same kind deteriorate rapidly under identical conditions. Our investigation provides new and significant information regarding physicochemical effects of potentiostatic pretreatment and demonstrates that pretreated $\mathrm{WO}_{3}$ films are not affected by $\mathrm{Li}^{+}$ion accumulation during electrochemical cycling. Changes of the films were related to compositional differences at the $\mathrm{WO}_{3} / \mathrm{ITO}$ and ITO/glass interfaces with In inter-diffusion in the $\mathrm{WO}_{3}$ film, and to the formation of carboncontaining solid-electrolyte interfacial layers on top of the $\mathrm{WO}_{3}$. Our results may be crucial for evading ageing and degradation of $\mathrm{WO}_{3}$-based electrochromic devices and for the development of purposefully designed electrodes of relevance also for other ion-based devices.

\section{Conflicts of interest}

There are no conflicts to declare.

\section{Acknowledgements}

MAA thanks the Mexican Council for Science and Technology (CONACyT) for financial support to work at Uppsala University as a postdoctoral researcher. Complementary financing was received from the European Research Council under the European Community's Seventh Framework Program (FP7/20072013)/ERC Grant Agreement No. 267234 (GRINDOOR). HYQ is grateful for financial support from the China Scholarship Council Doctoral Joint-Training Program. Support by VR-RFI (contracts \#821-2012-5144 \& \#2017-00646_9) and the Swedish Foundation for Strategic Research (SSF, contract RIF14-0053) supporting accelerator operation is gratefully acknowledged.

\section{References}

1 World Commission on Environment and Development, Our Common Future, Oxford University Press, London, UK, 1987.

2 N. Stern, The Economics of Climate Change: The Stern Review, Cambridge University Press, Cambridge, UK, 2007.

3 B. Obama, Science, 2017, 355, 126-129.

4 S. Pacala and R. Solocow, Science, 2004, 305, 968-972.

5 Buildings and Climate Change: Summary for Decision-Makers, United Nations Environmental Programme, Sustainable Buildings \& Climate Initiative, Paris, France, 2009.

62011 Buildings Energy Data Book, U.S. Department of Energy, Washington, DC, USA, 2012.

7 F. Favoino, M. Overend and Q. Jin, Appl. Energy, 2015, 156, 115.

8 M. Pittaluga, in Eco-Efficient Materials for Mitigating Building Cooling Needs: Design, Properties and Applications, ed. F. Pacheco-Torgal, J. A. Labrincha, L. F. Cabeza and C. G. Granqvist, Woodhead, Cambridge, UK, 2015, pp. 473-497.

9 R. D. Clear, V. Inkarojrit and E. S. Lee, Energy Build., 2006, 38, 758-779.
10 C. G. Granqvist, Handbook of Inorganic Electrochromic Materials, Elsevier, Amsterdam, The Netherlands, 1995.

11 G. B. Smith and C. G. Granqvist, Green Nanotechnology: Solutions for Sustainability and Energy in the Built Environment, CRC Press, Boca Raton, FL, USA, 2010.

12 Electrochromic Materials and Devices, ed. R. J. Mortimer, D. R. Rosseinsky and P. M. S. Monk, Wiley-VCH, Weinheim, Germany, 2015.

13 C. G. Granqvist, Thin Solid Films, 2014, 564, 1-38.

14 A. Llordes, E. L. Runnerstrom, S. D. Lounis and D. J. Milliron, in Electrochromic Materials and Devices, ed. R. J. Mortimer, D. R. Rosseinsly and P. M. S. Monk, WileyVCH, Weinheim, Germany, 2015, pp. 363-397.

15 C. G. Granqvist, M. A. Arvizu, İ. Bayrak Pehlivan, H.-Y. Qu, R.-T. Wen and G. A. Niklasson, Electrochim. Acta, 2018, 259, 1170-1182.

16 G. A. Niklasson and C. G. Granqvist, J. Mater. Chem., 2007, 17, 127-156.

17 S. Hashimoto and H. Matsuoka, J. Electrochem. Soc., 1991, 138, 2403-2408.

18 S. Hashimoto and H. Matsuoka, Surf. Interface Anal., 1992, 19, 464-468.

19 J. Göttsche, A. Hinch and V. Wittwer, Sol. Energy Mater. Sol. Cells, 1993, 31, 415-428.

20 F. S. Manciu, Y. Yun, W. G. Durrer, J. Howard, U. Schmidt and C. V. Ramana, J. Mater. Sci., 2012, 47, 6593-6600.

21 C. V. Ramana, G. Baghmar, E. J. Rubio and M. J. Hernandez, ACS Appl. Mater. Interfaces, 2013, 5, 4659-4666.

22 M. A. Arvizu, C. A. Triana, B. G. Stefanov, C. G. Granqvist and G. A. Niklasson, Sol. Energy Mater. Sol. Cells, 2014, 125, 184189.

23 F. Lin, D. T. Gillaspie, A. C. Dillon, R. M. Richards and C. Engtrakul, Thin Solid Films, 2013, 527, 26-30.

24 J.-H. Zhang, G.-F. Cai, D. Zhou, H. Tang, X.-L. Wang, C.-D. Gu and J.-P. Tu, J. Mater. Chem. C, 2014, 2, 7013-7021.

25 R.-T. Wen, G. A. Niklasson and C. G. Granqvist, ACS Appl. Mater. Interfaces, 2015, 7, 9319-9322.

26 Q. Liu, G. Dong, Q. Chen, J. Guo, Y. Xiao, M.-P. DelplanckeOgletree, F. Reniers and X. Diao, Sol. Energy Mater. Sol. Cell., 2018, 174, 545-553.

27 S.-H. Lee, R. Deshpande, P. A. Parilla, K. M. Jones, B. To, A. H. Mahan and A. C. Dillon, Adv. Mater., 2006, 18, 763-766.

28 F. Lin, J. Cheng, C. Engtrakul, A. C. Dillon, D. Nordlund, R. G. Moore, T.-C. Weng, S. K. R. Williams and R. M. Richards, J. Mater. Chem., 2012, 22, 16817-16823.

29 G. F. Cai, D. Zhou, Q. Q. Xiong, J. H. Zhang, X. L. Wang, C. D. Gu and J. P. Tu, Sol. Energy Mater. Sol. Cells, 2013, 117, 231-238.

30 R.-T. Wen, C. G. Granqvist and G. A. Niklasson, Nat. Mater., 2015, 14, 996-1001.

31 R.-T. Wen, C. G. Granqvist and G. A. Niklasson, ACS Appl. Mater. Interfaces, 2015, 7, 28100-28104.

32 R.-T. Wen, M. A. Arvizu, M. Morales-Luna, C. G. Granqvist and G. A. Niklasson, Chem. Mater., 2016, 28, 4670-4676.

33 R.-T. Wen, G. A. Niklasson and C. G. Granqvist, ACS Appl. Mater. Interfaces, 2016, 8, 5777-5782. 
34 M. A. Arvizu, C. G. Granqvist and G. A. Niklasson, J. Phys.: Conf. Ser., 2016, 764, 12009.

35 H.-Y. Qu, D. Primetzhofer, M. A. Arvizu, Z. Qiu, U. Cindemir, C. G. Granqvist and G. A. Niklasson, ACS Appl. Mater. Interfaces, 2017, 9, 42420-42424.

36 M. A. Arvizu, R.-T. Wen, D. Primetzhofer, J. E. KlembergSapieha, L. Martinu, G. A. Niklasson and C. G. Granqvist, ACS Appl. Mater. Interfaces, 2015, 7, 26387-26390.

37 B. Baloukas, M. A. Arvizu, R.-T. Wen, G. A. Niklasson, C. G. Granqvist, R. Vernhes, J. E. Klemberg-Sapieha and L. Martinu, ACS Appl. Mater. Interfaces, 2017, 9, 16995-17001.

38 M. A. Arvizu, H.-Y. Qu, G. A. Niklasson and C. G. Granqvist, Thin Solid Films, 2018, 653, 1-3.

39 A. J. Bard and L. R. Faulkner, Electrochemical Methods: Fundamentals and Applications, Wiley, New York, USA, 1980, p. 143.

40 P. Ström, P. Petersson, M. Rubel and G. A. Possnert, Rev. Sci. Instrum., 2016, 87, 103303.

41 K. S. Janson, CONTES: Conversion of Time-Energy Spectra: A Program for ERDA Data Analysis, Internal Report, Uppsala University, Sweden, 2004.

42 M. Mayer, AIP Conf. Proc., 1999, 471, 541-544.

43 D. Gogova, K. Gesheva, A. Szekeres and M. SendovaVassileva, Phys. Status Solidi A, 1999, 176, 969-984.

44 A. V. Naumkin, A. Kraut-Vass, S. W. Gaarenstroom and C. J. Powell, NIST X-ray Photoelectron Spectroscopy Database 20, Version 4.1, National Institute of Standards and Technology, Gaithersburg, MD, USA, 2012, http:// srdata.nist.gov/xps/.

45 M. Vasilopoulou, A. Soultati, D. G. Georgiadou, T. Stergiopoulos, L. C. Palilis, S. Kennou, N. A. Stathopoulos, D. Davazoglu and P. Argitis, J. Mater. Chem. A, 2014, 2, 1738-1749.

46 M. T. Martínez, M. A. Callejas, A. M. Benito, M. Cochet, T. Seeger, A. Ansón, J. Schreiber, C. Gordon, C. Marhic,
O. Chauvet, J. L. G. Fierro and W. K. Maser, Carbon, 2003, 41, 2247-2256.

47 T. I. T. Okpalugo, P. Papakonstantinou, H. Murphy, J. McLaughlin and N. M. D. Brown, Carbon, 2005, 43, 153161.

48 S. Kundu, Y. Wang, W. Xia and M. Muhler, J. Phys. Chem. C, 2008, 112, 16869-16878.

49 M. F. Daniel, B. Desbat, J. C. Lassegues, B. Gerand and M. Figlarz, J. Solid State Chem., 1987, 67, 235-247.

50 M. F. Daniel, B. Desbat, J. C. Lassegues and R. Gariem, J. Solid State Chem., 1988, 73, 127-139.

51 F. S. Manciu, J. L. Enriquez, W. G. Durrer, Y. Yun, C. V. Ramana and S. K. Gullapalli, J. Mater. Res., 2010, 25, 2401-2406.

52 D. Chatzikyriakou, N. Krins, B. Gilbert, P. Colson, J. Dewalque, J. Denayer, R. Cloots and C. Henrist, Electrochim. Acta, 2014, 137, 75-82.

$53 \mathrm{~K}$. Nakamoto, Infrared and Raman Spectra of Inorganic and Coordination Compounds, Part B, Wiley, Hoboken, NJ, USA, 6th edn, 2009.

54 S. Badilescu, P. V. Ashrit, F. E. Girouard and V.-V. Truong, J. Electrochem. Soc., 1989, 136, 3599-3602.

55 A. Rodes, E. Pastor and T. Iwasita, J. Electroanal. Chem., 1994, 376, 109-118.

56 A. Kraft, H. Hennig, A. Herbst and K.-H. Heckner, J. Electroanal. Chem., 1994, 365, 191-196.

57 D. Pletcher, J. F. Rohan and A. G. Ritchie, Electrochim. Acta, 1994, 39, 1369-1375.

58 K. Xu, Chem. Rev., 2014, 114, 11503-11618.

59 A. Maho, S. Nicolay, L. Manceriu, G. Spronck, C. Henrist, R. Cloots, B. Vertruyen and P. Colson, J. Electrochem. Soc., 2017, 164, H25-H31.

60 H.-J. Ahn, H.-S. Shim, Y.-E. Sung, T.-Y. Seong and W. B. Kim, Electrochem. Solid-State Lett., 2007, 10, E27-E30. 